http://dx.doi.org/10.19183/how.24.2.392

\title{
Editorial $^{*}$
}

\section{Moving Forward, in Times of Reforms in the Evaluation of Scientific Journals}

We are pleased to present the second issue of our twenty-fourth volume. This edition comes with the conviction of both the HOW journal and ASOCOPI that no matter what interests prevail in one's getting published or in the classification system that rules Colombian academic or scientific journals nowadays, it is worth it to persevere in sharing knowledge with our ELT (English language teaching) community within the country and overseas.

We understand that most university teachers are currently expected to publish in the so-called "prestigious," "international," and/or "well-ranked" journals. This is so because their publications have an impact on tenure of current positions, promotion or, in some cases, incentives represented by salary upgrades. In addition, publications become part of the indicators that universities wish to achieve for accreditation purposes. In connection with this, we have witnessed, in the inquiries received from authors or potential authors, that the majority of institutional policies are now more demanding in terms of the acceptance of publications for the purpose of incentives to be granted to those teachers who submit their publications to their corresponding evaluation bodies. Straightforward questions keep coming: "Are you classified in Scopus? Are you in Web of Science? Which quartile are you in: SJR or JCR?" Responses to these questions seem to be the reasons why many authors decide to contribute to specific academic or scientific journals nowadays. Scholars do need to respond to institutional requirements, to act in tune with the new policies that have been issued with the intention of improving the quality of publications edited in Colombia and to look for mechanisms that guarantee some salary increase. They are not to be blamed!

* Received: June 12, 2017. Accepted: June 19, 2017.

How to cite this article (APA 6th ed.):

Cárdenas, M. L. (2017). Editorial: Moving forward, in times of reforms in the evaluation of scientific journals. HOW, 24(2), 6-10. http://dx.doi.org/10.19183/how.24.2.392.

This article is licensed under a Creative Commons Attribution-NonCommercial-NoDerivatives 4.0 International License. License Deed can be consulted at http://creativecommons.org/licenses/by-nc-nd/4.0/. 
In 2011, Colciencias - the Colombian research agency in charge of the evaluation and classification of journals edited in the country-began to announce the changes to be introduced in IBN-Publindex (Índice Bibliográfico Nacional - Bibliographic National Index) (Rodríguez, 2011). Since then, many concerns have been raised by scholars, editorial teams, and scientific communities in local and international events. For instance, in 2014 the editors of various Latin-American journals met in Santiago, Chile, and expressed, among other things, their inconformity with the predominant systems of measuring the academic quality of publications in the region. Then, a Declaration was issued in 2015. HOW, like many other journals, adhered to it and published it (see HOW, Vol. 22, No. 2, 2015).

Critiques around new Colombian policies were more evident after the first drafts of the new policy document began to circulate in connection with the radical impact/changes that the new measures would have on journal classification. Negative effects were perceived, in particular, by scholars of the human sciences and arts areas because their possibilities to be classified under the new model (Colciencias, 2016b) were scarce. What is most important, those concerns, together with suggestions for policy revision, were made public via different forums, letters, and editorials.

Letters were sent to Colciencias expressing the inconvenience of the "Convocatoria 768", issued in 2016 (Colciencias, 2016a), with the purpose of producing the results of Colombian journals in the second semester of 2017. Some samples, to illustrate the critical perspective of Colombian scholars, are the letters sent by:

1. The participants of the national debate of scientific and academic journals (Debate Nacional de Revistas Académicas y Científicas: contribución a la evaluación del modelo Publindex de Colciencias) (December 16, 2016).

2. The Colombian Society of Philosophy (Sociedad Colombiana de Filosofía) (February 26, 2017).

3. The directors and editors of the Faculty of Human Sciences at Universidad Nacional de Colombia (May 23, 2017).

As mentioned in our latest issue (Cárdenas, 2017), the attempts of many editors, editorial centers, and universities to persuade Colciencias of the drawbacks of its new policies did not get the expected results. Letters signed by editors and university authorities as well as records of meetings in which editorial teams took part were sent, with arguments and evidences expressing that some of the contents of the new evaluation model are inappropriate for the Colombian context and current reality. The main and most common concern deals with the criterion that establishes the classification of Colombian journals depending on the quartile they occupy in either the JCR (Journal Citation Reports, led by Thomson) or the SJR (Scientific Journal Ranking, managed by Scopus). It should be noted that the classification in 
those indexing agencies depends upon the results of statistical analyses of citations received, that is to say, the Impact Factor (IF). Instead, and based on the idea of improving the impact of the national scientific publications, Colciencias decided to put into practice the criteria set out in its new policies (Colciencias, 2016b).

The issuance of the parameters for the improvement of quality in Colombian national scientific publications (Colciencias, 2016b) clearly shows that the autonomy in the definition of standards to evaluate them and the acceptance of a variety of criteria defined by local initiatives for Latin America, like SciELO, Redalyc, and Latindex, seem to be a matter of history. The evaluation they produce regarding quality of journals and their visibility were not taken into consideration as expected or suggested by many Colombian editors. For Colciencias, it is more important to act according to the indexing systems led in Britain or in the United States; their products were selected as the most important ones to measure the impact of scientific journals. The regional databases do not play a paramount role in the evaluation they will conduct.

Instead of maintaining the positive aspects of said regional initiatives and indexing systems in the evaluation criteria, Colciencias has now decided to mainly emulate mainstream journals - the ones published in the so-called developed countries-whose visibility is recognised by JCR or SJR. With the argument that we must have a higher impact on international scenarios, we are now obliged to serve the interests of the hegemonic regime of JCR, SJR, and the IF. Thus, the process for the new classification of Colombian journals is in progress.

Although the diagnostic evaluation carried out by Colciencias showed that HOW did not meet this visibility requirement (we are not in JCR or SJR yet), we cannot and should not give up. We have demonstrated that our journal plays an important role in the construction of local knowledge and in the maintenance of our professional ELT community. It is also "a space where the local and the global can co-mingle; where new understandings can emerge as a result of that interplay. The challenges ahead to ensure the sustainability of the journal and teachers' empowerment remain" (Cárdenas, 2014, p. 19).

With this belief in mind, we are pleased to present eight articles in this edition. This time, their contents deal with pedagogical processes in ELT, language policies, and teacher education. At the end, we also include a book review, which is expected to help us get acquainted with recent publications by Colombian scholars.

To begin with, the Research Reports section gathers seven articles. We begin with the article by Iranian authors Negar Moslemi and Adel Dastgoshadeh, who investigated the relationship between learners' cognitive styles and their preferences for different types and frequencies of written corrective feedback and for different types of errors to be corrected. Next, Andrés Rodríguez Sánchez, from Universidad del Norte, in Colombia, 
reports on the identification of the problems and needs of a group of secondary school students regarding their reading comprehension in English. We can then learn how the information gathered contributed to the designing and first implementation of a genreoriented syllabus.

The following contribution also comes from Iran. Authored by Razieh Gholaminejad, the article tells us about a qualitative study that aimed to explore whether Iranian English as a foreign language learners experience any reversal conceptual transfer and whether they construct two identities as a result of learning a foreign language.

Next, we have an article by Colombian teacher Adriana Castañeda-Londoño. She informs us about a small-scale action research that sought to identify teachers' perceptions about peer-coaching and their actual construction of knowledge in a peer-coaching activity carried out by three teachers in a private language center.

Following, we have the contribution by Chilean teachers Oliver Camilo Jorquera Torres, Jhon Eliot Mendoza Zapata, and Claudio Heraldo Díaz Larenas, who present an account of high school students' affective reaction to English speaking activities. In their report, we can find that teacher-researchers used individual and pair-based speaking activities, and then completed a semantic differential scale of nine bipolar adjectives to achieve their goal. Next, Colombian authors Maureyra Jiménez, Caroll Rodríguez, and Lourdes Rey Paba share with us the results of a study which sought to explore the relationship between the results obtained by a group of Industrial Engineering students in a national standardized English test and the impact these results had on language program improvement.

We close the first section of this edition with an article authored by Eric Gómez Burgos, from Chile. The author describes a project conducted in a public university with the purpose of exploring the use of the genre-based approach to teach expository essays to prospective teachers and the contributions it can make to students' writing competences.

The second section, Reports on Pedagogical Experiences, includes one report by Colombian authors Ana Clara Sánchez Solarte and Andrés Sánchez Solarte. Their project focused on the results of a group intervention based on strategies derived from the systemic therapy model — brief strategic therapy, with the intention of decreasing the anxiety levels commonly found in oral performance tasks related to L2 learning.

We close this edition with a Book Review contributed by Norbella Miranda, from Universidad del Valle (Colombia). She studied the book by Jaime Alonso Usma Wilches (from Universidad de Antioquia, Colombia), published in 2015. The book, entitled From Transnational Language Policy Transfer to Local Appropriation: The Case of the National Bilingual 
Program in Medellin, Colombia is, no doubt, a contribution to the study and implementation of language policies in our country.

As always, we hope you enjoy reading our journal and find its contents useful for your professional job. We also reiterate our invitation to take part in this editorial project which aims at providing spaces for teachers and researchers to get published, and which puts into practices the vision and mission of ASOCOPI, the Colombian Association of Teachers of English.

\section{Melba Libia Cárdenas}

Universidad Nacional de Colombia, Sede Bogotá

\section{Guest Editor}

\section{References}

Cárdenas, M. L. (2014). Publishing and academic writing: Experiences of authors who have published in PROFILE. PROFILE Issues in Teachers' Professional Development, 16(2), 11-20. http:/ / doi.org/10.15446/profile.v16n2.46144.

Cárdenas, M. L. (2017). Editorial. HOW, 24(1), 6-9. http://dx.doi.org/10.19183/how.24.1.349.

Colciencias. (2016a). Convocatoria No. 768 de 2016 para indexación de revistas científicas colombianas especializadas - Publindex (términos de referencia firmados). Bogotá, CO: Author. Retrieved from http:/ /www.colciencias.gov.co/sites/default/files/upload/convocatoria/terminosdereferencia-conv768-2016-firmados.pdf.

Colciencias. (2016b, Mayo). Documento No 1601: politica para mejorar la calidad de las publicaciones científicas nacionales (versión para discusión). Bogotá, CO: Author.

Declaration on citation indices and editorial practices. (2015). HOW, 22(2), 148-154.

Rodríguez, E. (2011, November 4). Publindex: un balance de 10 años y sus efectos en el SNCTI [PowerPoint presentation]. Bogotá, CO: Colciencias. 